\section{Formación en investigación en el pregrado para investigar y aprender}

Rosa María Bolívar Osorio

Hace apenas veinte años, pensar en que el pregrado debía formarnos para investigar en nuestras propias áreas era algo utópico reservado a los estudios de maestría y doctorado; pero gracias a la iniciativa de profesores y estudiantes de todo el país que lograron crear un movimiento con la consigna «a investigar se aprende investigando", lentamente se fue impulsando la cultura de formar en investigación desde el pregrado.

Es así como se resaltó la dimensión formativa de la investigación en la cual se entendió que quien investiga a la vez está aprendiendo sobre el oficio y sobre su objeto de estudio; de tal forma que hoy investigar y aprender son inseparables en cualquier proceso de formación.

En nuestras instituciones de educación superior, hoy una de las estrategias más consolidadas para apoyar estos procesos son los semilleros de investigación. En ellos se aprende y se investiga en comunidad y de manera articulada con los profesores formadores; por eso las investigaciones que resultan son tanto el logro de los estudiantes como de sus tutores.

La Corporación Universitaria Remington nos presenta hoy la nueva revista Investigar y Aprender creada con el propósito de visibilizar el trabajo de sus estudiantes de pregrado realizado en los semilleros de investigación o mediante la modalidad de trabajo de grado.

Es importante celebrar con esta comunidad la madurez a la que ha llegado su proceso que hoy les permite hacer un trabajo conjunto entre pro- fesores y estudiantes, además de tomar el riesgo de exponer ante la comunidad académica el resultado de sus elaboraciones. Esta revista tiene un lugar estratégico clave, desde el cual es posible seguirle apostando a que lo que hacen nuestros estudiantes. Es un trabajo serio que se juega en los cánones de las comunidades académicas a las que pertenecen, en el cual los hallazgos de sus investigaciones son relevantes y constituyen un aporte para los campos de los que provienen.

Nueve artículos componen este primer número, dos de ellos del área de derecho y los otros siete del área de la salud, sin duda un gran reto para próximos números es poder contar con artículos de las diferentes áreas temáticas en las cuales la institución también ha venido consolidando comunidades académicas.

En el área de Derecho estos estudiantes se muestran preocupados por los retos del nuevo sistema penal acusatorio y los retos a los que se enfrentan en el juicio oral. Desde el área de la Salud la dislipidemia y las citocinas en el adulto mayor hacen parte de los artículos de revisión, así como la giardiasis y desnutrición infantil.

Entre los artículos de investigación, el accidente ofídico, la bronquiolitis, el manejo de sobreanticoagulación por warfarina y las reacciones adversas relacionadas con el uso de medicamentos han sido los objetos de estudio de los equipos de profesores y estudiantes que decidieron emprender estos ejercicios de investigación.

Ahora queda el reto de seguir apostando por las nuevas generaciones, por la consolidación de estas comunidad $y$, sobre todo, mantener esta publicación con un alta calidad y con la periodicidad que se ha fijado de manera que se constituya en un gran escenario para la discusión de las novedades académicas que se derivan de nuestros procesos de investigación en el pregrado, para investigar $\mathbf{y}$ aprender. 